\title{
EphB/ephrinB Signaling in Cell Adhesion and Migration
}

\author{
Inji Park, and Hyun-Shik Lee*
}

Eph receptors and their ligands, ephrins, represent the largest group of the receptor tyrosine kinase (RTK) family, and they mediate numerous developmental processes in a variety of organisms. Ephrins are membrane-bound proteins that are mainly divided into two classes: $A$ class ephrins, which are linked to the membrane by a glycosylphosphatidylinositol (GPI) linkage, and B class ephrins, which are transmembrane ligands. Based on their domain structures and affinities for ligand binding, the Eph receptors are also divided into two groups. Trans-dimerization of Eph receptors with their membrane-tethered ligands regulates cell-cell interactions and initiates bidirectional signaling pathways. These pathways are intimately involved in regulating cytoskeleton dynamics, cell migration, and alterations in cellular dynamics and shapes. The EphBs and ephrinBs are specifically localized and modified to promote higher-order clustering and initiate of bidirectional signaling. In this review, we present an in-depth overview of the structure, mechanisms, cell signaling, and functions of EphB/ephrinB in cell adhesion and migration.

\section{INTRODUCTION}

Growth and maturation of an embryo requires synchronized communication of biochemical signals, which are mediated by protein-protein interactions between ligands and cell-surface receptors in early development. The EphB receptors and ephrinB ligands are cell surface proteins that influence cell behavior during embryogenesis and development (Batlle et al., 2002; Pasquale, 2008; Solanas et al., 2011). Eph receptors are expressed in all embryonic germ layers and mediate various functions, which include directing cell positioning and migration, axon guidance, patterning, and tissue morphogenesis during development. In addition, they also have diverse functions in tissue boundary formation, segmentation, and the development of the vascular system (Lee and Daar, 2009; Pasquale, 2005; Poliakov et al., 2005).

ABRC, CMRI, School of Life Sciences, BK21 Plus KNU Creative BioResearch Group, Kyungpook National University, Daegu 702-701, Korea

${ }^{*}$ Correspondence: : leeh@knu.ac.kr

Received 12 June, 2014; revised 14 October, 2014; accepted 17 October, 2014; published online 4 December, 2014

Keywords: cell adhesion, cell migration, development, EphB, ephrinB
There is significant and compelling evidence that Ephs and ephrins are mainly distributed into two groups, A and B, according to their binding specificities and sequence similarity with each other (Daar, 2012; Pasquale, 2008). Furthermore, upon Eph receptor and ephrin ligand binding, bidirectional signaling occurs, in which the Eph receptor is activated and transduces signaling within its own cell while signaling through ephrinB, which is known as reverse signaling, also takes place (Lee et al., 2009). In line with this concept, Eph forward and ephrin reverse signaling induces cell repulsion, and controls cellular shape changes that mediate both repulsive and migratory responses (Chong et al., 2000; Park et al., 2011; Winning et al., 2001). The ephrinB class is best known for reverse signaling, as members of this class have highly conserved intracellular tyrosine residues within the cytoplasmic domain that become phosphorylated upon contact with Eph receptors. These ligands also possess a carboxyl-terminal PDZ-binding motif that is important for ephrinB reverse signaling (Lee et al., 2006; Pasquale, 2008). This review describes EphB/ephrinB signaling and interactions with a number of other molecules during morphogenesis and development.

\section{STRUCTURE OF EPH/EPHRIN COMPLEX}

The Eph receptor family belongs to the largest class of RTKs, and their extracellular domain consists of a highly conserved $\mathrm{N}$ terminal ligand-binding domain, a cysteine-rich region, which is composed of an epidermal growth factor (EGF)-like motif, and two fibronectin type III repeats (Himanen et al., 2001; Pasquale, 2005). Studies have shown that the cytoplasmic portion of Eph receptors contains a tyrosine kinase domain and protein-protein interacting modules, including a sterile- $\alpha$-motif (SAM) as well as PDZ-binding motif (Pasquale et al., 2008). The SAM domain is a protein-interacting domain that promotes homodimerization and oligomerization of the receptors. The PDZ-binding motif mediates organization of protein complexes at the plasma membrane (Zisch et al., 2000). The ephrin-binding domain of EphBs has a high-affinity binding site that mediates biochemical communication between Ephs and ephrins in adjacent cells (Himanen et al., 2007; Wimmer-Kleikamp and Lackmann, 2005). Alternatively, two low-affinity ephrin-binding sites mediate the clustering of multiple Eph-ephrin complexes (Himanen et al., 2010).

EphrinBs also contain an extracellular receptor-binding domain followed by a cytoplasmic portion that is phosphorylated upon receptor binding (Himanen et al., 2001). The interaction domains of EphB receptors and ligands join, forming heterodi- 


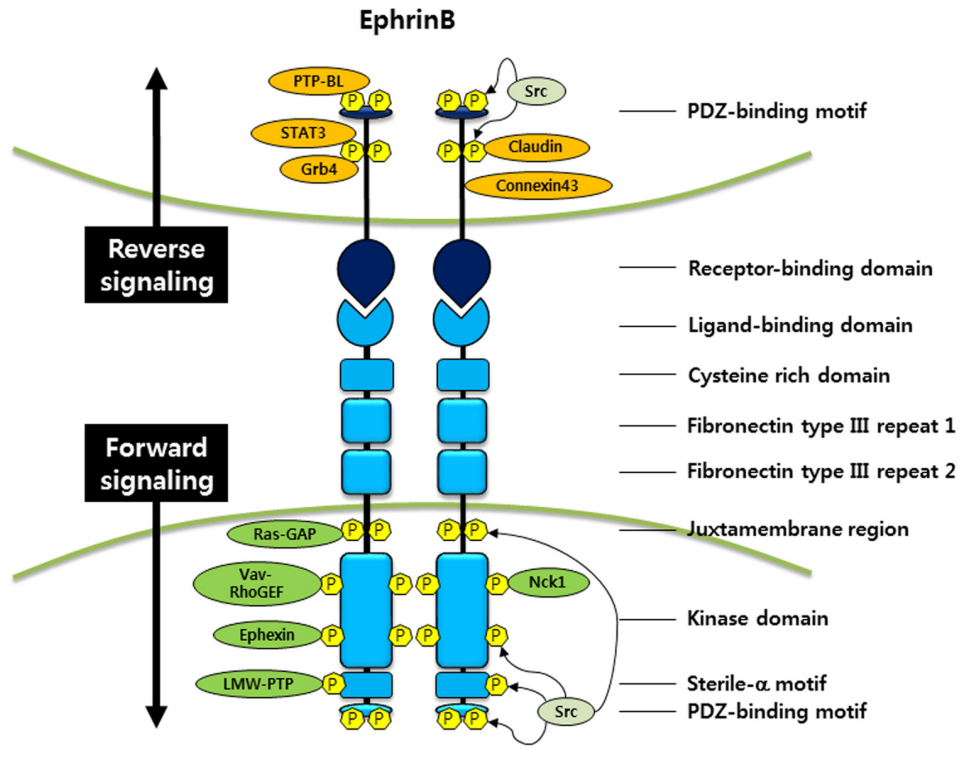

Eph
Fig. 1. Phosphorylation-dependent EphB/ephrinB signaling. EphB binds to ephrinB, which has a short cytoplasmic region for reverse signaling. Forward signaling by the EphB receptor requires ligand binding and controls actin remodeling, cell migration, cell-cell adhesion, and other developmental events through the recruitment of various interacting molecules to EphB receptor. In addition, ephrinB reverse signaling is accomplished by receptorligand binding and phosphorylation of tyrosine residues on ephrinB1 cytoplasmic domain. Phosphorylated ephrinB recruits various interacting proteins to modulate many biological processes including cell adhesion, migration, and gene expressions. mers that subsequently form heterotetramers (Himanen et al., 2010). The heterodimer and heterotetramer interfaces center around the G-H loop of the ephrinBs, which is inserted deep within a channel on the surface of the EphBs (Himanen et al., 2001; Pasquale et al., 2008). To evaluate the exact structural complex, further studies are needed to determine the number of possible EphB-ephrinB binding states, which will elucidate the molecular details of the binding interactions.

\section{MECHANISM OF EPH/EPHRIN SIGNALING}

Eph/ephrin signaling begins with physical contact and sequential clustering of receptor-ligand complex to form high-affinity heterotetramer complex (Himanen et al., 2010; Seiradake et al., 2010). Eph forward signaling activates intrinsic tyrosine kinase through tyrosine phosphorylation, which recruits Rho family guanine nucleotide exchange factors that regulate Rho-family GTPases, thus modulating cellular shape and adhesive properties. The SH2-adaptor proteins Nck1 and Vav-RhoGEFs have been implicated in this signaling process, since they bind with EphBs and induce EphB2-dependent endocytosis (Cowan et al., 2005; Holland et al., 1996) (Fig. 1). In addition, binding of EphBs with ephrinBs stimulates attachment through the recruitment of low-molecular-weight phosphotyrosine phosphatase (LMW-PTP) and dorsolateral migration of neural crest cells (melanoblasts) in chicken embryos (Santiago and Erickson, 2002; Stein et al., 1998) (Fig. 1). It is believed that Eph/ephrin signaling initially blocks and then enhances the migration of neural crest cells in a dorsolateral direction through activation of the Cdc42/ Rac family of GTPases (Santiago and Erickson, 2002).

Activation of EphA4 receptors due to ligand binding augments the ability of ephexin to activate RhoA and inhibits the ability of ephexin to activate Rac1 and Cdc42, leading to a shift in the balance between Rho GTPase activities. This activity ultimately results in growth cone collapse during axon extension (Sahin et al., 2005). It also has been reported that a negative regulator of RhoA, RasGAP, interacts with EphBs (Elowe et al., 2001) (Fig. 1). EphrinB binding to the EphB receptor tyrosine kinase triggers phosphorylation of ephexin5, which negatively regulates excitato- ry synapse development, resulting in ephexin ubiquitination and degradation (Margolis et al., 2010). EphrinB ligands can recruit PDZ domain proteins through their carboxy-terminal (YYKV) target sites (Bush and Soriano, 2009) (Fig. 1).

EphrinB transmembrane ligands lack intrinsic catalytic activity and utilize scaffolding activity for signaling and cell function. EphrinB reverse signaling involves both phosphorylationdependent and -independent signal transduction. Phosphorylation-dependent signaling involves tyrosine phosphorylation of ephrinB on one or more of the five to six conserved tyrosines in the short cytoplasmic domain (Brückner et al., 1997; Holland et al., 1996). This phosphorylation event occurs upon binding to the cognate Eph receptor, which resides on another cell, and results from the recruitment and activation of a Src family member and a regulatory phosphotyrosine phosphatase (PTP-BL) (Palmer et al., 2002) (Fig. 1). Once tyrosine residues on cytoplasmic domain of ephrinB are phosphorylated, $\mathrm{SH}_{2} / \mathrm{SH}_{3}$ domain-containing proteins, such as the adaptor protein growth-factor-receptor-bound protein 4 (Grb4) is recruited and binds to ephrinB, which facilitates cytoskeletal remodeling (Brückner et al., 1997; Cowan and Henkemeyer, 2001; Holland et al., 1996) (Fig. 1). Another such protein is the Signal Transducer and Activator of Transcription 3 (STAT3) protein, and interaction between ephrinB and STAT3 reveals that ephrin $B$ transduces its own signaling activity from the cell surface to the nucleus (Bong et al., 2007; Jørgensen et al., 2009). In the case of ephrinB2, the interaction with STAT3 has been suggested to be important for orchestrating pericyte/ endothelial cell assembly (Salvucci et al., 2009). In addition to phosphorylation of ephrinBs in response to binding to their cognate receptors, alternative growth factor receptors, such as the fibroblast growth factor receptor (FGFR), platelet-derived growth factor receptor (PDFGR), epidermal growth factor receptor (EGFR), and the TIE2 receptor, can interact with ephrinBs, induce the phosphorylation of ephrinBs (Adams et al., 1999; Brückner et al., 1997; Chong et al., 2000; Palmer et al., 2002; Thelemann et al., 2005) and regulate ephrinBs signaling during embryogenesis (Lee et al., 2009; Moore et al., 2004). Additionally, FGFR-mediated phosphorylation of ephrinB1 has been shown to recruit Grb4 in Xenopus cell signaling (Bong et al., 2004) (Fig. 1). 
Phosphorylation-independent signaling begins with unphosphorylated ephrinB, which interacts with protein complexes; this protein complex produces a signal affecting cell-cell interactions, and the signal is maintained until tyrosine phosphorylation of ephrinB occurs. Upon tyrosine phosphorylation, the interaction between ephrin $\mathrm{B}$ and the other protein is disrupted (Daar, 2012; Lee et al., 2008; 2009; Xu and Henkemeyer, 2012). A significant portion of phosphorylation-independent reverse signaling is transduced by an interaction with PDZ domain proteins that associate with the C-terminal PDZ-binding motifs of ephrinBs (Kalo and Pasquale, 1999). Mutation of the ephrinB1 PDZ binding motif causes abnormalities of the forebrain axon tract in the corpus callosum (Bush and Soriano, 2009). In endothelial cells, the PDZ-binding motif of ephrinB2 is essential for organization and activation of vascular endothelial growth factor receptors (VEGFR)-2 and VEGFR-3 (Wang et al., 2010). VEGF and Notch signaling also regulate ephrinB2 expression during blood vessel morphogenesis, and both have potential roles in vessel growth and arterial differentiation (TorresVazquez et al., 2003). For example, mice that lack ephrinB2 have reduced angiogenesis and developed abnormal yolk sac vasculature (Adams et al., 1999; Wang et al., 1998). Moreover, ephrinB2 expression mediates dorsal aorta formation and prevents unnecessary ventral sprouting (Gerety and Anderson, 2002).

To disengage Eph/ephrin signaling, the interaction between Eph and ephrin must be disrupted. Two mechanisms are known to disrupt this interaction: endocytosis and proteolytic cleavage. Once ephrinBs bind to their cognate receptors, the internalization of the receptor-ligand complexes immediately occurred during cell retraction (Marston et al., 2003; Zimmer et al., 2003). Interactions between EphB- and ephrinB-positive cells induce formation of intracellular vesicles that contain the full-length proteins in a complex; therefore, the process is dependent on intracellular signaling pathways (Marston et al., 2003; Pitulescu and Adams, 2010; Zimmer et al., 2003). Previous studies have shown that EphB1 induces clustering and subsequent endocytosis of ephrinB1, which is mediated by a clathrin-dependent pathway (Parker et al., 2004).

In the case of proteolytic cleavage, there are membraneassociated metalloproteases (e.g., presenilin, MMPs, ADAMs) that can cleave both ephrins and Eph receptors (Georgakopoulos et al., 2006; Hattori et al., 2000; Janes et al., 2005; 2009; Ji et al., 2014; Tanaka et al., 2007). The cleavage by these metalloproteases of both ephrinA and ephrinB proteins leads to internalization and degradation of ephrins, clearing them from the cell surface and consequently breaking the adhesion between cells. The balance between forward and reverse endocytosis (either being endocytosed into the contacting cell or into the cell of residence for the ephrin ligand) depends on many cell types, receptor/ligand type, surface densities, oligomerization states, and activation of downstream signaling pathways (Marston et al., 2003; Pitulescu and Adams, 2010; Zimmer et al., 2003).

\section{EPHRINB1 IN CELL-CELL ADHESION}

Eph/ephrin signaling controls several aspects of cell-cell adhesion, which is required for the maintenance of intercellular communication and the connection between epithelial cells. This process is very important for initiating normal morphogenetic movements during development and organogenesis. Cellcell adhesion is necessary for maintenance of complex cellular structures that are primarily mediated through tight junctions (TJs), adherens junctions (AJs), desmosomes, and gap junc- tions (Perez-Moreno and Fuchs, 2006). EphB signaling supports the formation of epithelial cell junctions through an interaction with E-cadherin, and when this association is inhibited, AJs form abnormally. E-cadherin-dependent intercellular adhesion can regulate Eph receptor expression and activation (Cortina et al., 2007; Noren and Pasquale, 2007). Thus, differential adhesion can occur when ephrinB1 is mutated, particularly in the PDZ-binding motif (Solanas et al., 2011).

Several years ago, evidence revealed that over-expression of ephrinB1 in Xenopus embryos causes the blastomeres of ectodermal tissue to dissociate (Chong et al., 2000; Jones et al., 1998). Genetic evidence clearly shows that the intracellular domain of ephrinBs is critical for neural crest movement, tissue border formation, and vascular morphogenesis; these roles demonstrate that this domain has signaling functions (Adams et al., 2001; Davy et al 2004; Dravis and Henkemeyer, 2011; Herbert et al., 2009; Makinen et al., 2005). Recently, interaction of ephrinB1 and Smad ubiquitin regulatory factors (Smurfs) has been shown to be important for tissue separation at mesoderm/ectoderm boundaries. EphrinB1 is degraded by Smurf2, whereas Smurf1 prevents this degradation. During embryonic mesoderm development, inhibition of Smurf1 results in loss of ephrinB1-mediated separation of tissue from the ectoderm, thus affecting the formation of tissue boundaries (Hwang et al., 2013). The Smurf ubiquitin ligases regulate tissue separation via antagonistic interactions with ephrinB1 (Hwang et al., 2013). An important aspect of ephrinB reverse signaling in particular, that is starting to be recognized is the role of ephrinBs in affecting cell-cell junctions. For example, it has been reported that, in embryonic ectoderm, unphosphorylated ephrinB1 binds Par-6, which is a member of the Par polarity complex, to keep Par-6 from interacting with activated small G protein Cdc42-GTP (Lee et al., 2008). Reduction in the Par-6/Cdc42-GTP interaction inhibits aPKC activation, leading to TJ dissolution. Tyrosine phosphorylation of ephrinB1 prevents an interaction with Par-6, leaving it available to interact with Cdc42-GTP and establish TJs (Lee et al., 2008). In the absence of ephrinB1, Par-6, which is usually localized to AJs and lateral cell borders, may compete with apically localized Par- 6 to active Cdc42. This may effectively reduce available active $\mathrm{Cdc} 42$ at the apical border, resulting in a reduction of aPKC activity and disruption of TJs. An alternative explanation is that an unspecified cell adhesion protein that normally interacts with ephrinB1 at the lateral border loses its functionality in the absence of ephrinB1, resulting in dissolution of TJs and AJs (Fig. 2). Another recent study showed that ephrinB2 reverse signals may be phosphorylationindependent and involve interactions with either the PDZbinding domain or claudin molecules, which are a major component of TJs (Dravis and Henkemeyer, 2011).

Interaction between EphrinB1 and claudin has been shown to regulate cell-cell adhesions. Claudin, located in the subapical region of the lateral membrane, can directly interact with Eph/ephrin proteins in epithelial cells. Interaction between claudin and ephrinB1 induces tyrosine phosphorylation of ephrinB1, and this influences intracellular-substrate adhesion (Tanaka et al., 2005). Moreover, compelling evidence has shown that ephrinB1 regulates gap junction communication by forming a complex with Connexin 43, which participates in morphogenetic processes during development (Davy et al., 2006). Additionally, functional deletion of ephrinB signaling restricts cell integration and blocks gap junction communication, which leads to calvarial bone defects (Davy et al., 2006). Further research is needed to explore the precise mechanism of how ephrinB1 regulates gap junctiondependent cell adhesion. 


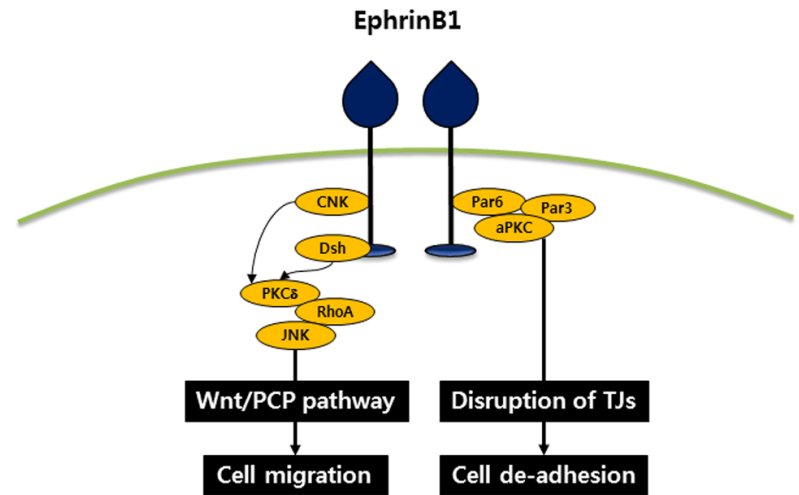

Fig. 2. Phosphorylation-independent ephrinB1 signaling. EphrinB1 promotes cell migration through the activation of Wnt/PCP pathway by interacting with CNK1 and Dsh. In addition, ephrinB1 interacts Par-6, and sequentially releases Cdc42-GTP from intact Par polarity complex, which has a major role in stabilizing TJs. Finally, accumulation of unphosphorylated ephrinB1 in TJs causes disruption of TJs and cell adhesion.

EphrinB1-null mutant mice exhibit neuroepithelial morphological defects and demonstrate that ephrinB1 plays a significant role in neural tube closure (Arvanitis et al., 2013). Using electroporation ex vivo, it was found that ephrinB1 is required to maintain apical adhesion of apical progenitors. This cell-cell adhesion is accomplished through $\mathrm{SH} 2-$ and PDZ-dependent ephrinB1 reverse signaling, which inhibits ADP-ribosylation factor 6 in the progenitors and controls integrin-based adhesion (Arvanitis et al., 2013). Eph/ephrin interactions also control the cell positioning, which is negatively regulated by Wnt signaling compared with other ephrinBs (Batlle et al., 2002; van de Wetering et al., 2002). EphrinB1 expression has been reported to involve in cell positioning in the small intestine, and this expression is much higher at the villus-crypt boundary in adult mice compared with newborns (Batlle et al., 2002). In transgenic mice with a negative receptor in the intestinal epithelium, ephrinB1-associated cells are distributed along the crypt-villus axis (Batlle et al., 2002).

\section{EPHRINB1 IN CELL MIGRATION}

Cell migration is dependent on cell-cell adhesion, which is required for formation, stabilization, and positioning of morphogenetic processes during development. Cell migration consists of multiple processes such as lamellipodium extension, nascent adhesion formation, cell body retraction, and tail detachment. In particular, Eph/ephrin signaling promotes integrin-mediated cell adhesion, and integrins are transmembrane receptors that activate signal transduction and cause cell migration (Huynh-do et al., 1999). The EphB1 receptor and ephrinB1 activate the Nck/NIK (Nck-interacting Ste20 kinase) pathway via interaction with the adaptor protein Nck to up-regulate c-Jun N-terminal kinase (JNK) and mediate attachment and cell migration (Becker et al., 2000). EphrinB1 also increases focal adhesion kinase (FAK) activation, which plays a crucial role in integrin signaling (Becker et al., 2000).

Recently, a phosphorylation-independent ephrinB1 interaction with the connector and enhancer of KSR1 (CNK1), which increases cell motility, has been reported. This interaction increases RhoA-dependent activation of JNK. This study also revealed that the ephrinB1 interaction with CNK1 and the resultant activation of JNK is dependent on Src activation through integrins and not through an interaction with the cognate Eph receptor. In addition, silencing of CNK1 or inhibition of Rho blocks ephrinB1induced cell migration as well as JNK activation (Cho et al., 2014). In line with this, we have shown that ephrinB1 regulates eye development by modulating the Wnt/planar cell polarity (PCP) pathway through interactions with Xenopus Dishevelled (Dsh), which affects RhoA activity (Lee et al., 2006) (Fig. 2). Interestingly, phosphorylation of ephrinB1 via the FGFR perturbs its interaction with Dsh, thus disengaging the PCP pathway from ephrinB1 and inhibiting retinal progenitor movement (Lee et al., 2009; Moore et al., 2004). EphrinB activation causes phosphorylation of Dab1 (a key regulator of Reelin signaling) through Src family kinases in neurons, and functional loss of ephrinBs induces aberrant neuronal migration (Senturk et al., 2011; $\mathrm{Xu}$ and Henkemeyer, 2012). Moreover, the protein-tyrosine phosphatase, PTB-BL, functions as a negative regulator of ephrinB phosphorylation as well as inactivation of Src family kinases (Palmer et al., 2002).

During Xenopus development, various ephrinBs and Eph receptors are required for repositioning of germ layers on both sides of the cell borders, and tissue separation between ectoderm and mesoderm depends on Eph forward signaling across the boundary in both directions. This signaling involves some degree of redundancy among ligands and receptors as well as activation of Rac and RhoA (Rohani et al., 2011). Additionally, activation of ephrinB1 increases tyrosine phosphorylation of Cas and the Crk adaptor protein (Nagashima et al., 2002). This Cas/Crk signaling activates Rap1 and SHEP1, both of which mediate cell migration (Dodelet et al., 1999). The EphB1 receptor can regulate cell migration via interactions with an $\mathrm{SH} 2$ adapter protein, Grb7, and phosphorylation of the SAM domain of EphB1 (Han et al., 2002).

\section{CONCLUSION}

In the last decade, a great deal of research has clarified that Eph and ephrin proteins use bidirectional signaling to control developmental processes. Because of the complexity of Eph/ephrin signaling and the distinct effect on cell behavior, the underlying molecular mechanisms regarding developmental functions are still being revealed. Other intriguing issues are the divergence of Eph/ephrin clustering and endocytosis as well as whether EphB1 and ephrinB1 can interact with other surface proteins that can control cell adhesion and migration. Future studies will reveal the developmental roles of Eph and ephrin proteins in adult physiology and plasticity, which will hopefully give rise to a wide array of therapeutic opportunities.

\section{ACKNOWLEDGMENTS}

This research was supported by the Basic Science Research Program through the National Research Foundation of Korea (NRF) funded by the Ministry of Education, Science and Technology (NRF-2012R1A1A2042334) and by a grant from the Next-Generation BioGreen 21 Program (PJ009564), Rural Development Administration, Republic of Korea.

\section{REFERENCES}

Adams, R. H., Wilkinson, G. A., Weiss, C., Diella, F., Gale, N. W. Deutsch, U., Risau, W. and Klein, R. (1999). Roles of ephrinB ligands and EphB receptors in cardiovascular development: demarcation of arterial/venous domains, vascular morphogenesis, and sprouting angiogenesis. Genes Dev. 13, 295-306. 
Adams, R.H, Diella, F., Hennig, S., Helmbacher, F., Deutsch, U. and Klein, R. (2001). The cytoplasmic domain of the ligand ephrinB2 is required for vascular morphogenesis but not crania neural crest migration. Cell 104, 57-69.

Arvanitis, D.N., Béhar, A., Tryoen-Tóth, P., Bush, J.O., Jungas, T. Vitale, N., and Davy, A. (2013). Ephrin B1 maintains apical adhesion of neural progenitors. Development 140, 2082-2092.

Batlle, E., Henderson, J.T., Beghtel, H., van den Born, M.M., Sancho, E., Huls, G., Meeldijk, J., Robertson, J., van de Wetering, M., Pawson, T., et al. (2002). Beta-catenin and TCF mediate cell positioning in the intestinal epithelium by controlling the expression of EphB/ephrinB. Cell 111, 251-263.

Becker, E., Huynh-Do, U., Holland, S., Pawson, T., Daniel, T.O. and Skolnik, E.Y. (2000). Nck-interacting Ste20 kinase couples Eph receptors to c-Jun $\mathrm{N}$-terminal kinase and integrin activation. Mol. Cell. Biol. 20, 1537-1545.

Bong, Y.S., Park, Y.H., Lee, H.S., Mood, K., Ishimura, A., and Daar, I.O. (2004). Tyr-298 in ephrinB1 is critical for an interaction with the Grb4 adaptor protein. Biochem. J. 377, 499-507.

Bong, Y.S., Lee, H.S., Carim-Todd, L., Mood, K., Nishanian, T.G. Tessarollo, L., and Daar, I.O. (2007). ephrinB1 signals from the cell surface to the nucleus by recruitment of STAT3. Proc. Natl. Acad. Sci. USA 104, 17305-17310.

Brückner, K., Pasquale, E.B., and Klein, R. (1997). Tyrosine phosphorylation of transmembrane ligands for Eph receptors. Science 275, 1640-1643.

Bush, J.O., and Soriano, P. (2009). Ephrin-B1 regulates axon guidance by reverse signaling through a PDZ-dependent mechanism. Genes Dev. 23, 1586-1599.

Cho, H.J., Hwang, Y.S., Mood, K., Ji, Y.J., Lim, J., Morrison, D.K., and Daar, I.O. (2014). EphrinB1 Interacts with CNK1 and Promotes Cell Migration through JNK Activation. J. Biol. Chem. 289, 18556-18568

Chong, L.D., Park, E.K., Latimer, E., Friesel, R., and Daar, I.O. (2000). Fibroblast growth factor receptor-mediated rescue of $X$ ephrin B1-induced cell dissociation in Xenopus embryos. Mol. Cell. Biol. 20, 724-734.

Cortina, C., Palomo-Ponce, S., Iglesias, M., Fernandez-Masip, J.L., Vivancos, A., Whissell, G., Huma, M., Peiro, N., Gallego, L., Jonkheer, S., et al. (2007). EphB-ephrin-B interactions suppress colorectal cancer progression by compartmentalizing tumor cells. Nat. Genet. 39, 1376-1383.

Cowan, C.A., and Henkemeyer, M. (2001). The SH2/SH3 adaptor Grb4 transduces B-ephrin reverse signals. Nature 413, 174-179.

Daar, I.O. (2012). Non-SH2/PDZ reverse signaling by ephrins. Semin. Cell Dev. Biol. 23,65-74.

Davy, A., Aubin, J., and Soriano, P. (2004). Ephrin-B1 forward and reverse signaling are required during mouse development. Genes Dev. 18, 572-583.

Davy, A., Bush, J.O., and Soriano, P. (2006). Inhibition of gap junction communication at ectopic Eph/ephrin boundaries underlies craniofrontonasal syndrome. PLoS Biol. 4, e315.

Dodelet, V.C., Pazzagli, C., Zisch, A.H., Hauser, C.A., and Pasquale, E.B. (1999). A novel signaling intermediate, SHEP1, directly couples Eph receptors to R-Ras and Rap1A. J. Biol. Chem. 274, 31941-31946.

Dravis, C., and Henkemeyer, M. (2011). Ephrin-B reverse signaling controls septation events at the embryonic midline through separate tyrosine phosphorylation-independent signaling avenues. Dev. Biol. 355, 138-151.

Elowe, S., Holland, S.J., Kulkarni, S., and Pawson, T. (2001). Downregulation of the Ras-mitogen-activated protein kinase pathway by the EphB2 receptor tyrosine kinase is required for Ephrin-induced neurite retraction. Mol. Cell. Biol. 21, 7429-7441.

Georgakopoulos, A., Litterst, C., Ghersi, E., Baki, L., Xu, C., Serban, G., and Robakis, N.K. (2006). Metalloproteinase/Presenilin1 processing of ephrinB regulates EphB-induced Src phosphorylation and signaling. EMBO J. 25, 1242-1252.

Gerety, S.S., and Anderson, D.J. (2002). Cardiovascular ephrinB2 function is essential for embryonic angiogenesis. Development $129,1397-1410$

Han, D.C., Shen, T.L., Miao, H., Wang, B., and Guan, J.L. (2002). EphB1 associates with Grb7 and regulates cell migration. J. Biol. Chem. 277, 45655-45661.

Hattori, M., Osterfield, M., and Flanagan, J.G. (2000). Regulated cleavage of a contact-mediated axon repellent. Science 289 ,
1360-1365.

Herbert, S.P., Huisken, J., Kim, T.N., Feldman, M.E., Houseman, B.T., Wang, R.A., Shokat, K.M., and Stainier, D.Y. (2009). Arterial-venous segregation by selective cell sprouting: An alternative mode of blood vessel formation. Science 326, 294-298.

Himanen, J.P., Rajashankar, K.R., Lackmann, M., Cowan, C.A. Henkemeyer, M., and Nikolov, D.B. (2001). Crystal structure of an Eph receptor-ephrin complex. Nature 414, 933-938.

Himanen, J.P., Saha N., and Nikolov, D.B. (2007). Cell-cell signaling via Eph receptors and ephrins. Curr. Opin. Cell Biol. 19, 534542.

Himanen, J P., Yermekbayeva, L., Janes, P.W., Walker, J.R., Xu, K., Atapattu, L., Rajashankar, K.R., Mensinga, A., Lackmann, M., Nikolov, D.B., et al. (2010). Architecture of Eph receptor clusters. Proc. Natl. Acad. Sci. USA 107, 10860-10865.

Holland, S.J., Gale, N.W., Mbamalu, G., Yancopoulos, G.D., Henkemeyer, M., and Pawson, T. (1996). Bidirectional signalling through the EPH-family receptor Nuk and its transmembrane ligands. Nature 383, 722-725.

Hwang, Y.S., Lee, H.S., Kamata, T., Mood, K., Cho, H.J., Winterbottom, E., Ji, Y.J., Singh, A., and Daar, I.O. (2013). The Smurf ubiquitin ligases regulate tissue separation via antagonistic interactions with ephrinB1. Genes Dev. 27, 491-503.

Huynh-Do, U. Stein, E., Lane, A.A. Liu, H., Cerretti, D.P., and Daniel, T.O. (1999). Surface densities of ephrin-B1 determine EphB1coupled activation of cell attachment through alphavbeta3 and alpha5beta1 integrins. EMBO J. 18, 2165-2173.

Janes, P.W., Saha, N., Barton, W.A., Kolev, M.V., WimmerKleikamp, S. H., Nievergall, E., Blobel, C. P., Himanen, J. P., Lackmann, M., and Nikolov, D.B. (2005). Adam meets Eph: an ADAM substrate recognition module acts as a molecular switch for ephrin cleavage in trans. Cell 123, 291-304.

Janes, P.W., Wimmer-Kleikamp, S.H., Frangakis, A.S., Treble, K., Griesshaber, B., Sabet, O., Grabenbauer, M., Ting, A.Y., Saftig, P., Bastiaens, P.I., et al. (2009). Cytoplasmic relaxation of active Eph controls ephrin shedding by ADAM10. PLoS Biol. 7, e1000215.

Ji, Y.J., Hwang, Y.S., Mood, K., Cho, H.J., Lee, H.S., Winterbottom, E., Cousin, H., and Daar, I.O. (2014). EphrinB2 affects apical constriction in Xenopus embryos and is regulated by ADAM10 and flotillin-1. Nat. Commun. 5, 3516.

Jørgensen, C., Sherman, A., Chen, G.I., Pasculescu, A., Poliakov, A,, Hsiung, M., Larsen, B., Wilkinson, D.G., Linding, R., and Pawson, T. (2009). Cell-specific information processing in segregating populations of Eph receptor ephrin-expressing cells. Science 326, 1502-1509.

Jones, T.L., Chong, L.D., Kim, J., Xu, R.H., Kung, H.F., and Daar, I.O. (1998). Loss of cell adhesion in Xenopus laevis embryos mediated by the cytoplasmic domain of XLerk, an erythropoietinproducing hepatocellular ligand. Proc. Natl. Acad. Sci. USA 95, 576-581.

Kalo, M.S., and Pasquale, E.B. (1999). Signal transfer by eph receptors. Cell Tissue Res. 298, 1-9.

Lee, H.S., and Daar, I.O. (2009). EphrinB reverse signaling in cellcell adhesion: is it just par for the course? Cell Adh. Migr. 3, 250255.

Lee, H.S., Bong, Y.S., Moore, K.B., Soria, K., Moody. S.A., and Daar, I.O. (2006). Dishevelled mediates ephrinB1 signalling in the eye field through the planar cell polarity pathway. Nat. Cell. Biol. 8, 55-63.

Lee, H.S., Nishanian, T.G., Mood, K., Bong, Y.S., and Daar, I.O. (2008). EphrinB1 controls cell-cell junctions through the Par polarity complex. Nat. Cell. Biol. 10, 979-986.

Lee, H.S., Mood, K., Battu, G., Ji, Y.J., Singh, A., and Daar, I.O. (2009). Fibroblast growth factor receptor-induced phosphorylation of ephrinB1 modulates its interaction with dishevelled. Mol. Biol. Cell. 20, 124-133.

Makinen, T., Adams, R.H., Bailey, J., Lu, Q., Ziemiecki, A., Alitalo, K., Klein, R., and Wilkinson, G.A. (2005). PDZ interaction site in ephrinB2 is required for the remodeling of lymphatic vasculature. Genes Dev. 19, 397-410.

Marston, D.J., Dickinson, S., and Nobes, C.D. (2003). Racdependent transendocytosis of ephrinBs regulates Eph-ephrin contact repulsion. Nat. Cell Biol. 5, 879-888.

Margolis, S.S., Salogiannis, J., Lipton, D.M., Mandel-Brehm, C., Wills, Z.P., Mardinly, A.R., Hu, L., Greer, P.L., Bikoff, J.B., Ho, 
H.Y., et al. (2010). EphB-mediated degradation of the RhoA GEF Ephexin5 relieves a developmental brake on excitatory synapse formation. Cell 143, 442-455.

Moore, K.B., Mood, K., Daar, I.O., and Moody, S.A. (2004). Morphogenetic movements underlying eye field formation require interactions between the FGF and ephrinB1 signaling pathways. Dev. Cell 6, 55-67.

Nagashima, K., Endo, A., Ogita, H., Kawana, A., Yamagishi, A., Kitabatake, A., Matsuda, M., and Mochizuki, N. (2002). Adaptor protein Crk is required for ephrin-B1-induced membrane ruffling and focal complex assembly of human aortic endothelial cells. Mol. Biol. Cell. 13, 4231-4242.

Noren, N.K., and Pasquale, E.B. (2007). Paradoxes of the EphB4 receptor in cancer. Cancer Res. 67, 3994-3997.

Palmer, A. Zimmer, M., Erdmann, K.S., Eulenburg, V., Porthin, A., Heumann, R., Deutsch, U., and Klein, R. (2002). EphrinB phosphorylation and reverse signaling: regulation by Src kinases and PTP-BL phosphatase. Mol. Cell 9, 725-737.

Park, E.C., Cho, G.S., Kim, G.H., Choi, S.C., and Han, J.K. (2011) The involvement of Eph-Ephrin signaling in tissue separation and convergence during Xenopus gastrulation movements. Dev. Biol. 350, 441-450.

Parker, M., Roberts, R., Enriquez, M., Zhao, X., Takahashi, T., Pat Cerretti, D., Daniel, T., and Chen, J. (2004). Reverse endocytosis of transmembrane ephrin-B ligands via a clathrin-mediated pathway. Biochem. Biophys. Res. Commun. 323, 17-23.

Pasquale, E.B. (2005). Eph receptor signaling casts a wide net on cell behaviour. Nat. Rev. Mol. Cell Biol. 6, 462-475.

Pasquale, E.B. (2008). Eph-ephrin bidirectional signaling in physiology and disease. Cell 133, 38-52.

Perez-Moreno, M., and Fuchs, E. (2006). Catenins: keeping cells from getting their signals crossed. Dev. Cell 11, 601-612.

Pitulescu, M.E., and Adams, R.H. (2010). Eph/ephrin molecules-a hub for signaling and endocytosis. Genes Dev. 24, 2480-2492.

Poliakov, A., Cotrina, M., and Wilkinson, D.G. (2005). Diverse roles of eph receptors and ephrins in the regulation of cell migration and tissue assembly. Dev. Cell 7, 465-480.

Rohani, N., Canty, L., Luu, O., Fagotto, F., and Winklbauer, R. (2011). EphrinB/EphB signaling controls embryonic germ laye separation by contact-induced cell detachment. PLoS Biol. 9, e1000597.

Sahin, M., Greer, P.L., Lin, M.Z., Poucher, H., Eberhart, J., Schmidt, S., Wright, T.M., Shamah, S.M., O'Connell, S., Cowan, C.W., et al. (2005). Eph-dependent tyrosine phosphorylation of ephexin1 modulates growth cone collapse. Neuron 46, 191-204.

Salvucci, O., Maric, D., Economopoulou, M., Sakakibara, S., Merlin, S., Follenzi, A., and Tosato, G. (2009). EphrinB reverse signaling contributes to endothelial and mural cell assembly into vascular structures. Blood 114, 1707-1716.

Santiago, A., and Erickson, C.A. (2002). Ephrin-B ligands play a dual role in the control of neural crest cell migration. Development 129, 3621-3632.

Seiradake, E., Harlos, K., Sutton, G., Aricescu, A.R., and Jones, E.Y. (2010). An extracellular steric seeding mechanism for Ephephrin signaling platform assembly. Nat. Struct. Mol. Biol. 17, 398-402.
Senturk, A., Pfennig, S., Weiss, A., Burk, K., and Acker-Palmer, A. (2011). Ephrin Bs are essential components of the Reelin pathway to regulate neuronal migration. Nature 472, 356-360.

Solanas, G., Cortina, C., Sevillano, M., and Batlle, E. (2011) Cleavage of Ecadherin by ADAM10 mediates epithelial cell sorting downstream of EphB signalling. Nat. Cell Biol. 13, 11001107.

Stein, E., Lane, A.A., Cerretti, D.P., Schoecklmann, H.O., Schroff, A.D., Van Etten, R.L., and Daniel, T.O. (1998). Eph receptors discriminate specific ligand oligomers to determine alternative signaling complexes, attachment, and assembly responses. Genes Dev. 12, 667-678.

Tanaka, M., Kamata, R., and Sakai, R. (2005). Phosphorylation of ephrin-B1 via the interaction with claudin following cell-cell contact formation. EMBO J. 24, 3700-3711.

Tanaka, M., Sasaki, K., Kamata, R., and Sakai, R. (2007). The Cterminus of ephrin-B1 regulates metalloproteinase secretion and invasion of cancer cells. J. Cell Sci. 120, 2179-2189.

Thelemann, A., Petti, F., Griffin, G., Iwata, K., Hunt, T., Settinari, T., Fenyo, D., Gibson, N., and Haley, J.D. (2005). Phosphotyrosine signaling networks in epidermal growth factor receptor overexpressing squamous carcinoma cells. Mol. Cell Proteomics 4, 356-376.

Torres-Vazquez, J., Kamei, M., and Weinstein, B.M. (2003). Molecular distinction between arteries and veins. Cell Tissue Res. 314, 43-59.

van de Wetering, M., Sancho, E., Verweii, C., de Lau, W., Oving, I., Hurlstone, A., van der Horn, K., Batlle, E., Coudreuse, D., Haramis, A.P., et al. (2002). The $\beta$-catenin/TCF-4 complex imposes a crypt progenitor phenotype on colorectal cancer cells. Cell 111, 241-250.

Wang, H.U., Chen, Z.F., and Anderson, D.J. (1998). Molecular distinction and angiogenic interaction between embryonic arteries and veins revealed by ephrin-B2 and its receptor Eph-B4 Cell 93, 741-753.

Wang, Y., Nakayama, M., Pitulescu, M.E., Schmidt, T.S., Bochenek, M.L., Sakakibara, A., Adams, S., Davy, A., Deutsch, U., Luthi, U., et al. (2010). Ephrin-B2 controls VEGF-induced angiogenesis and lymphangiogenesis. Nature 465, 483-486.

Wimmer-Kleikamp, S.H., and Lackmann, M. (2005). Ephmodulated cell morphology, adhesion and motility in carcinogenesis. IUBMB Life 57, 421-431.

Winning, R.S., Wyman, T.L., and Walker, G.K. (2001). EphA4 activity causes cell shape change and a loss of cell polarity in Xenopus laevis embryos. Differentiation 68, 126-132.

$\mathrm{Xu}$, N.J., and Henkemeyer, M. (2002). Ephrin reverse signaling in axon guidance and synaptogenesis. Semin. Cell Dev. Biol. 23, 58-64.

Zimmer, M., Palmer, A., Kohler, J., and Klein, R. (2003). EphBephrinB bidirectional endocytosis terminates adhesion allowing contact mediated repulsion. Nat. Cell Biol. 5, 869-878.

Zisch, A.H., Pazzagli, C., Freeman, A.L., Schneller, M., Hadman, M., Smith, J.W., Ruoslahti, E., and Pasquale, E.B. (2000). Replacing two conserved tyrosines of the EphB2 receptor with glutamic acid prevents binding of $\mathrm{SH} 2$ domains without abrogating kinase activity and biological responses. Oncogene 19,177-187. 